\title{
NETATIVISMO E INDIGNAÇÃO NA ESFERA PÚBLICA
}

\section{NETACTIVISM AND INDIGNATION IN THE PUBLIC SPHERE}

\author{
João Carlos CORREIA ${ }^{1}$
}

\begin{abstract}
Resumo: Uma das consequências da aparição da sociedade em rede foi a diferenciação estrutural introduzida na noção de espaço público, verificada pelo impacto das redes sociais num ambiente comunicativo caracterizado pela aceleração significativa das trocas simbólicas, induzidas pelos meios digitais, nomeadamente redes sociais e comunicações móveis. Uma das características centrais desta diferenciação é a apropriação de modelos de comunicação alargada, desenvolvidos pelas redes sociais. Estes modelos de comunicação por um lado são potenciadores da construção, partilha e vivência alargada de experiências colaborativas. Por outro lado, refletem redes informais de comunicação que convergem num novo modelo de configuração hegemónica. Assim traduzem modelos contraditórios de globalização. Qual é a qualidade do discurso público e em que medida traduz um ganho epistêmico resultante do exercício dos modelos de comunicação colaborativa em rede? Que efeitos na comunicação pública são suscetíveis de serem identificados nos novíssimos movimentos sociais? Qual o significado do diálogo público nas novas condições de interação geradas por novos dispositivos e plataforma? De que forma as trocas simbólicas na rede expressam na sua materialidade a reconfiguração das estruturas do espaço público e da ação política? Qual o papel da literacia digital na possível reconfiguração destes modelos comunicativos? Tendo em conta as manifestações portuguesas de indignados contra a austeridade, questionamos o impacto dos media digitais no mundo da vida e na esfera publica online em tempos marcados por uma comunicação cada vez mais móvel. Segundo o ponto de vista adotado, a comunicação online e o desmpenho do utilizador num ambiente móvel produziram uma vasta quantidade de possibilidades relacionadas com a configuração da ação coletiva no espaço público que reflectem as vicissitudes induzidas pela nova ecologia mediática.
\end{abstract}

Palavras-chave: Netavismo; Esfera Pública; Movimentos Sociais; Europa

\begin{abstract}
One of the main consequences of the appearance of the network society was the structural differentiation introduced the notion of public sphere induced by the impact of social networks in a communicative environment characterized by a significant acceleration of symbolic exchanges by digital media, including social networks and mobile communications. One of the central features of this differentiation is the appropriation of expanded communication models developed by social networks. These models of communication by one hand are enhancing the building and sharing of collaborative experiences. On the other hand, they reflect the informal communication networks that converge on a new configuration of the hegemonic model, expressing contradictory models of globalization. What is the quality of public discourse and to what extent reflects an epistemic gain resulting from the exercise of collaborative models of networked communication? What effects on public communication are likely to be identified in the new social movements? What the public dialogue does on new interaction conditions generated by new devices and platforms? In what way symbolic networked interactions expressed in its
\end{abstract}

\footnotetext{
${ }^{1}$ Professor do Departamento de Comunicação da Universidade da Beira Interior, Portugal. Coordenador do LabCom.IFP - jcfcorreia@gmail.com
} 


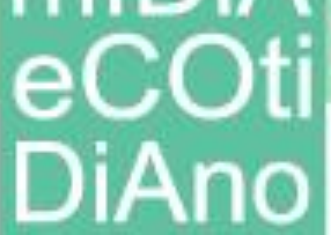

materiality the reconfiguration of the structures of public sphere and political action? What's the role of digital literacy in the possible shaping of those communicative models? Bearing in mind the Portuguese demonstration of indignation against austerity, we question the impact of digital media in the online lifeworld and in public sphere in times of increasing mobile communication. According to the adopted point of view, mobile online communication and user performances produced a vast amount of possibilities regarding the configuration of collective action in the public sphere that reflect changes induced by the new media ecology.

Keywords: Netactvism; Public Sphere; Social Movements; Europe 


\section{Introdução}

O problema das redes e da sua relação com o discurso público e com os processos deliberativos que acompanham o chamado Netativismo não pode ser desligada de um conceito de sujeito social, que resultou de uma narrativa que focalizou especialmente os fenómenos da multi-pertença e da fragmentação de papéis políticos dos atores sociais e de seus contextos envolventes.

Durante os primeiros estudos sobre a Internet, muitos acadêmicos puseram sua ênfase na identidade pessoal enquanto disembodied self, sublinhando o apego à contingência identitária e a libertação dos constrangimentos pessoais e sociais numa perspectiva individualista.

Acreditava-se que as tecnologias sociais da internet emancipariam os agentes sociais do determinismo que acompanhava o seu agenciamento, permitindo-lhes explorar de forma lúdica as suas múltiplas personae escolhendo uma versão melhorada ou pelo menos, entendida como mais livre, da sua identidade (Rheingold, 1993, Turkle, 1995). As raízes e o local perdiam o determinismo constangedor. Estas narrativas, então convincentes, hoje superadas pelas suspeitas sobre a vigilância e o controle social ligadas à Web 2.0., interessaram-se especialmente pelos fenômenos de multi-pertença e a fragmentação crescente dos contextos e regulações sociais.

Ao mesmo tempo, a percepção dominante da política (especialmente, entre os mais jovens) configurou uma forte descrença nas regras de organização da sociedade civil. De uma certa forma, os atores sociais cujo agenciamento é cada vez mais conectado, sentem-se vítimas de poderes abstratos dos quais se sentem incapazes de se evadir ou controlar as forças econômicas, sociais e ambientais que estes desencadeiam. Entidades como sejam as corporações, as redes, as organizações supranacionais e os imperativos factuais da geoestratégia parecem mais vigorosos do que qualquer genuíno sentimento deliberativo. Os sistemas políticos movimentos e processos que dominaram os últimos duzentos anos parecem já não dispor de eficácia transformadora. A democracia e as escolhas econômicas, geralmente associadas ao exercício do poder 


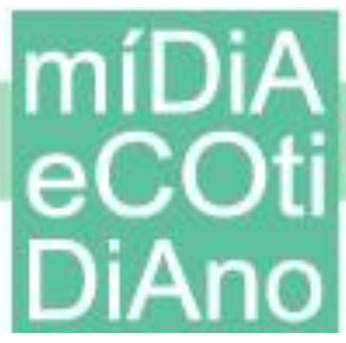

soberano, são limitadas em níveis supracionais que regulam a estabilidade laboral e o peso da carga fiscal com tanta ou mais capacidade soberana que os próprios governos e tornam os estados uma realidade com poderes limitados que suscitam desconfiança cidadã. Para tal, contribuem as estruturas da própria globalização hegemónica (WTO, IMF) e a aceleração da velocidade nas transações financeiras.

Os partidos políticos de centro-esquerda conhecem uma dificuldade crescente em impor-se como alternativa credível e procuram reinventar-se ou através de novas fórmulas governativas (Portugal) ou soçobram dando origem a novos movimentos políticos (Syriza na Grécia, Podemos em Espanha), movimentos sociais, e rebeliões espontâneas. A social-democracia surge aprisionada entre a sua apropriação em coligações com o centro-direita (SPD alemão) que acabam por se reduzir em soluções austeritárias ou regressam a fórmulas cuja consistência, capacidade apelativa e durabilidade é ainda carente de prova: Jeremy Corbyrn, Bernie Sanders.

Quanto aos movimentos "radicais" vale a pena perguntar que marca produziram nos modelos de discussão pública e nas consequências políticas da sua atividade. As páginas do facebook relativas a Movimentos, como sejam a Geração à Rasca ou Que se Lixe a Troika (coletivos ativistas que desencaderam protestos de indignação em Portugal no contexto da crise da dívida pública) provam que, muitos, quando interrogados sobre o objetivo das manifestações, dão conta de como os participantes admitem uma sensação diferenciada de realização. Quando olhamos para os protestos e para suas diversas formas de expressão online, verifica-se que geram processos de agendamento ou até novos enquadramentos para os temas em debate, mas não é clara a prova empírica de que os efeitos pretendidos (quando existem) sejam alcançados.

Apesar destes elementos que compõem o background europeu no contexto da crise da dívida pública soberana, o renascimento do ativismo tornou-se outra vez muito evidente nas manifestações contra a austeridade, desemprego e precariedade. Desde 2008, ativistas ocuparam praças e ruas estabelecendo a agenda, num processo que pareceu simultaneamente flexível, autónomo e suscetível de ser compreendido pelo conceito de multidões, o qual abrange uma diversidade fluída de movimentos que parecem disponíveis para relacionarem e constituírem redes. O conceito de multidão 
abrange o poder de indivíduos qualificados, que se relacionam entre si num mundo em que a inovação acelera consideravelmente, com os cursos tecnológicos diminuindo substancialmente (Hardt e Negri, 2004).

Obviamente os métodos que estes estratos utilizam são o produto de uma mudança social bem identificada protagonizada pelos participantes numa mutação social em que o "trabalho está a ser transformada sobre a hegemonia do trabalho imaterial, isto é trabalho que produz produtos imateriais, como sejam informação, ideias, imagens, etá relações e afetos" (Hardt e Negri, 2004, p.65). Este processo

It is part of an ongoing youth-driven social upheaval born out of a technological revolution, a period of enhanced economic liberalization, the spread of international civil society initiatives, and a tightening of the security state (Herrera., 2015: 21).

Quer no caso Europeu quer contestações que se verificaram nos países árabes que chamaram a atenção para as redes sociais, o cenário é relativamente idêntico:

Our concern here is particularly with the growing and demographically dominant population of high school and university-educated youth born in the period from the 1970s to the early years of the millennium, who have been active in both virtual spaces and on the streets (Herrera, 2015: 22).

Neste cenário de incerteza, esta nova geração experimentou taxas exponenciais de conetividade ao mesmo tempo que se confrontava com uma considerável perda de enraizamento ao nível político e económico, enfrentando o desmantelamento de redes de segurança tradicionais, elevadas taxas de desemprego e precaridade e taxas crescentes de desigualdade no acesso aos recursos que proporcionam mobilidade.

No caso das revoluções em que intervêm as gerações educadas no âmbito das tecnologias digitais, estas não podem ser ignoradas nem desprezadas enquanto fenómeno que há muito vinha criando condições objetivas para a sua utilização política. Na verdade, os jogos de vídeo, a televisão por cabo e por satélite e a internet faziam já parte de um processo global e eram responsáveis por um forte impulso econômico. Esse impulso econômico tinha regenerado um novo protagonismo ao fenômeno da comunicação, gerando empregos, formações universitárias e transferência de competências. 
Formou-se, deste modo, um novo tipo de intelectual associado à classe média simultaneamente emergente sob o ponto de vista académico (massificação do ensino) mas ameaçado sob o ponto de vista económico (proletarização, precaridade e desemprego).

Apesar das tradicionais mensagens "apocalípticas ou integradas", não é possível deixar de reconhecer que, à medida que os mais jovens absorveram as tecnologias nas suas vidas, começando desde muito cedo nas suas práticas lúdicas nos jogos de computadores e de vídeo, essas tecnologias criaram a percepção de uma ruptura na autoridade tradicional da família e do Estado. De fato, independentemente de nos interrogarmos sobre as verdadeiras consequências políticas, não é possível deixar de ignorar que uma geração inteira já cresceu acostumada a um elevado nível de interatividade e de participação (cf. Herrera, Idem).

From the alter-globalization struggles of the late 1990s, through the antiwar and ecological coalitions of the early 2000s, and into the new student uprisings and Occupy movements since 2008, a common pattern emerges: resistance struggles rise rapidly, mobilize increasingly large numbers of people, and yet fade away only to be replaced by a renewed sense of apathy, melancholy and defeat. Despite the desires of millions for a better world, the effects of these movements prove minimal (Srnicek, 2015: 21).

\section{O papel da internet no espaço publico.}

A análise da configuração epistemológica dos debates públicos passou pelo conceito de espaço público sujeito a intenso reexame desde a sua formulação clássica por Jurgen Habermas. Este apresentou a esfera pública como um espaço de liberdade onde os seus participantes se reconhecem como livres e iguais, demonstrando a racionalidade dialógica gerada na discussão das pessoas privadas reunidas num público (Habermas, 1982: 78-79).

Nas formulações posteriores, a esfera pública materializou-se numa rede de sensores localizados no interior da sociedade, sensíveis às pressões dos problemas coletivos e, também, como una caixa-de-ressonância que amplifica a pressão dos problemas, tematizando-os e dramatizando-os de modo a serem assumidos e considerados pelos decisores. A influência política dos atores assenta, em última instância, no acordo de um público de leigos que possui os mesmos direitos e que tem 


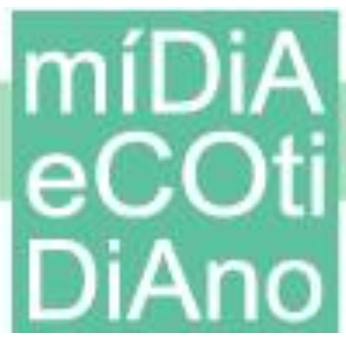

de ser convencido através de contribuições compreensíveis e interessantes sobre temas que eles consideram ser relevantes (Habermas, 1996).

O modelo unitário de esfera pública foi sendo progressivamente abandonado para, em seu lugar, se erguer a atenção a uma rede heterogénea de públicos que podem inclusive repensar, renegociar e reconsiderar questões controversas, geralmente excluídas da agenda, desenvolvendo uma especial sensibilidade para temas que ficam confinados à periferia da sociedade civil (cf. Fraser, 1992). Foi convocada a noção de espaços públicos oposicionais (counter public spheres) por oposição a uma esfera pública monolítica e exclusivista (cf. Silva e Garcia, 2011: 90). Porém, a pertinência desta categoria sociológica terá de ser repensada desde o interior de um universo onde surgem outros elementos de análise.

A abordagem "distópica" referiu uma série de desvantagens e obstáculos que negam o papel político da internet no alargamento destes espaços públicos diversos e plurais. O espaço público foi modificado, mas isso não significou necessariamente um alargamento do direito de comunicar (George, 2001, p.24). A participação de audiências não significou necessariamente um aumento da qualidade da cidadania já que também aumentaram as possibilidades de as pessoas depreciarem pontos de vista alternativos (Sunstein: 2001, p.49). As redes sociais, com suas causas e grupos temáticos, seriam responsáveis de ambiente fragmentado, com impacto negativo sobre o diálogo racional democrático (Fenton, 2009, p.8-9). Estabeleceu-se uma ligação direta entre a internet e as dinâmicas culturais da "globalização neoliberal", como força ideológica que muda o papel e a natureza dos meios de comunicação nas sociedades modernas (Hassan, 2004). Avistaram-se sinais de que os padrões de produção capitalista transformaram a internet num meio comercial, menos vocacionado para a promoção de práticas democráticas (Papacharissi, 2004: 20).

Finalmente, a economia-mundo e a ordem da informação, triangulada em torno da União Europeia, Estados Unidos e Ásia, garantiram que os fluxos informativos centrados na produção de conteúdos desempenhassem um papel decisivo na difusão da ideologia liberal (cf. Proulx, 2002). Sob um ponto de vista mais diretamente orientado para a política, é impossível ignorar-se uma vasta influência do Departamento de Estado 
Americano em muitas formas de dissidência ativa, com destaque para países onde os interesses americanos são claramente alinhados com a oposição ao Governo.

Apesar de tudo, as novas tecnologias facilitaram o envolvimento dos cidadãos na observação e interpretação dos acontecimentos. A tecnopolítica e tactical media serviram como como experiências de novos meios contra-hegemónicos que foram usados pelos grupos e indivíduos que se sentiram excluídos do diálogo publico e da cultura hegemónica. Assim, um movimento híbrido ganhou expressão crescente. O ativismo na NET foi encarado como sendo um mix de velho e de novo, assombrado pela geografia, gênero, raça e outros fatores políticos. Como se considera incorreta a partilha de uma concepção nominalista e essencialista do espaço público, julga-se mais produtivo verificar como as práticas simbólicas e discursivas funcionam na nova ecologia mediática, configurando a própria ideia de participação pública. Assim, não se acredita num ideal-tipo normativo de participação pública configurado como padrão que estabelece as potencialidades na NET para o ativismo. Antes se prefere indagar de que modo, as próprias práticas e discursos envolvidos nas redes sociais desencadeam novas configurações na participação nestes espaços públicos. Valoriza-se, por isso, a atenção a grupos com novos potenciais de intervenção e de relação com a realidade (curadores, artistas, ativistas digitais, programadores, especialistas em design e comunicação) os quais facilitam a libertação de gramáticas e de léxicos diferenciados, marcados pelo hedonismo, pela ironia, pela paródia e pela caricatura, pelo intertextualismo e dialogismo, pela iconografia e pela econoclastia e, por isso, não tão centrados na racionalidade cognitiva e instrumental expressa por um programa, um conjunto de objetivos claros e a clareza de métodos para os atingir. Neste sentido, além do conceito de público, parece-nos que o conceito de multidão parece desempenhar um papel interessante, para se referir a uma realidade multifaceteda, contraditória e dotada de capacidade de inovação criativa.

O "espaço público híbrido" (Castells, 2012) constituído neste ciclo de protesto, formado da articulação entre a ação nas redes sociais online e a ocupação do espaço público físico das cidades, deu origem a novas escalas de ação, a novas formas de mobilização e organização, marcadas pela cultura da rede, pela comunicação horizontal, por mecanismos colaborativos de trabalho, pela tentativa de evitar lideranças, pela mistura e combinação de referências internacionais (Soeiro, 2014: 61). 
Assistiu-se a emergência recente de formas de sociabilidade que agem politicamente com discussão interna e intervenção crítica, exibindo traços de públicos racionais ou características de fluidez e espontaneidade próprias das chamadas multidões. Por detrás destas novas formas de organizar movimentos sociais, encontramse novidades contraditórias: a insistência nas artes performativas e nos modos ritualistas de expressão como parte da comunicação pública; o uso de reuniões deliberativas para comunicar com extratos diversificados da população (recentemente em Lisboa, numa conferência sobre o tema, ativistas LGBT do Podemos contavam como se dirigiram a manifestantes homofóbicos durante os acontecimentos de Puertas del Sol para argumentarem pontos de vista, gerando inesperadas situações de conversação). Alguns dos elementos ritualistas parecem confirmar a afirmação de Pascal segundo a qual muitos "são frequentemente conduzidos para a crença, não pela evidência mas pela afeção" (Pascal cit. por LeBon, s/d.). De modo alternativo, o uso de fóruns e assembleias de rua (acampadas, como foram designados pelos indignados) parecem almejar pôr em prática, de modo informal, alguma racionalidade discursiva e argumentativa, embora de um modo informal e expontâneo.

Tal abordagem conduz a Revolução Web 2.0, que permitiu a abertura de modos pedagogicamente vitais de acesso às tecnologias de produção digital. As possibilidades de transformação cívica das novas tecnologias de produção e comunicação manifestamse em cada vídeo de movimentos como "Que se lixe a troika" ou "Geração à Rasca", os quais se transformam em parte do ambiente mediático. Os jovens interagem com essas histórias como consumidores e produtores de notícias.

O fulcro da discussão consiste no aparecimento de critérios que nos permitem assistir à configuração da natureza pública da comunicação, aparecimento este tornado possível pelas mudanças profundas nos dispositivos comunicacionais e pelas novas possibilidades entreabertas de divulgar versões alternativas por grupos excluídos. Tal como o espaço público liberal era permanentemente desafiado com novos mecanismos de representação, visibilidade e reconhecimento que progressivamente permiram o aperecimento de temas que eram geralmente confinados ao espaço privado (género, etnicidade e ambiente entre um conjunto de causas batizadas como "políticas da vida"), 
não nos devemos surpreender que o impacto da Internet na esfera pública contemporânea não tenha sido uma exceção idiossincrática e que por isso os dispositivos móveis e o ambiente mediático tenham produzido uma série de parâmetros fluidos de configuração, de comunicação virtual online.

\section{Indignação no espaço público}

Os espaços chamados de "indignados", pela sua heterogeneidade e pela intervenção das redes sociais, tornaram ainda mais pertinente elaboração de uma interpelação diferente sobre concepção de esfera pública e por isso, a necessidade de uma inquietação teórica que contemple com igual suspeita a formação de multidões. Ao abordar-se muitas das expressões de protesto analisando as manifestações de protesto encontram-se, ao tempo, características distintivas muito interessantes, as quais podem ser vislumbradas em trabalhos sobre manifestação de 12 de Março de 2011, em Lisboa (Correia, 2011), sobre os indignados espanhóis ou sobre as revoluções árabes, cujos trágicos desenvolvimentos não devem fazer esquecer de modo nenhum os genuínos desenvolvimentos democráticos que acompanharam o seu aparecimento.

No primeiro caso referido (2011), após um apelo público feito em 7 de fevereiro por quatro trabalhadores - estudantes jovens a viver em condições de precaridade, $\mathrm{o}$ número de pessoas disponíveis para participarem na manifestação que expressou essa disponibilidade através do Facebook ascendia a 18700. Em 3 de março atingia 37 mil pessoas. O números geralmente apontado pelos jornais indicou cerca de 500 mil participantes nas manifestações de 12 de março em Lisboa e Porto, as duas principais cidades portuguesas. No auge do movimento, as páginas das redes sociais fervilhavam de vídeos, canções, selfies e testemunhos autobiográficos, que davam uma particular dimensão à participação na manifestação: os atores estavam simultaneamente on e offline ou, melhor dito, estavam numa situação em que a disparidade entre as duas categorias não fazia sentido. De uma forma geral, a análise dos movimentos portugueses anti-austeridade enunciam as mesmas características comuns: um discurso centrado na denúncia do sistema econômico e na captura das instituições e agentes políticos pelo poder financeiro; a exigência de "mais" ou de uma "verdadeira" democracia; a 


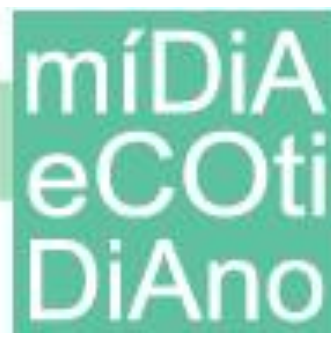

juventude precarizada como catalisadora de lutas sociais mais amplas; uma certa recusa da delegação e um ceticismo mais ou menos ressentido em relação à ação institucional; a produção de novas referências plásticas e estéticas; a ocupação transgressiva do espaço público; a valorização da diversidade de expressão nos protestos de rua; o uso intensivo das redes sociais; a importância da cultura audiovisual e das novas tecnologias de informação e comunicação; a busca de formas tendencialmente horizontais de organização (Soeiro, 2014: 57).

Por outro lado, este movimento desencadeiou um ciclo de protestos: por ordem cronológica, o 15 de outubro de 2011 (Dia de Ação Global), a greve geral de 24 de novembro de 2011 (organizada conjuntamente pela Confederação Geral dos Trabalhadores Portugueses - CGTP e pela União Geral de Trabalhadores - UGT), a Primavera Global de 12 de maio de 2012, o 15 de setembro de 2012 (Que se Lixe a Troika), o 13 de outubro de 2012 (manifestações culturais do Que se Lixe a Troika) e a greve geral com dimensão europeia de 14 de novembro de 2012 (que aconteceu em Portugal, Grécia, Espanha, Malta e Chipre) (cf. Soeiro: 2014).

Os nossos próprios estudos deram particular ênfase à forma como estes novíssimos movimentos sociais se interrelacionaram com as redes, detectando alguns elementos comuns:

1. Forte investimento emocional. O momento de maior participação nas páginas da rede social do Facebook é também o momento em que a componente celebrativa e festiva é mais intensa. Ao invés, a curva relacionada com o ceticismo sofre uma ligeira ascensão nos momentos em que a participação diminui e os participantes colocam a questão "o que vamos fazer a seguir?"

2. Escassa ou residual identificação política, sendo todavia possível identificar um espectro muito vasto de opções políticas ideológicas díspares nos poucos posts que explicitamente apresentam um posicionamento desse tipo. A esta, associa-se uma forte rejeição da classe política o que produziu avisos de vozes que alertam para os riscos de esta opção traduzir uma clara desvalorização da democracia representativa, mesmo que nunca assumida ou consciencializada enquanto tal. 
3. Ausência de uma agenda detalhada. Os temas são bem identificados mas escassamente desenvolvidos, verificando-se a preocupação de "deixar os detalhes para mais tarde". Trata-se de um fenômeno que se traduz na sensação de que a própria proposta de um programa parece macular a pretendida inocência do movimento.

\begin{abstract}
In more recent struggles, the very idea of making demands has been questioned. The Occupy movement infamously struggled to articulate meaningful goals, worried that anything too substantial would be divisive. 3 And a broad range of student occupations across the Western world has taken up the mantra of 'no demands' under the misguided belief that demanding nothing is a radical act (Nick Srnicek, 2015: 25).
\end{abstract}

\title{
3. Pluralidade de elementos participativos, designadamente o recurso à ironia.
}

Os movimentos trouxeram traços completamente distintivos em relação a elementos fundamentais da caracterização clássica da esfera pública como a fragmentação e o papel atribuído à racionalidade estético-expressiva. Verificou-se o uso de léxicos e recursos simbólicos com configurações marcadas pela atenção à linguagem icónica, aos elementos multimediáticos e ao uso da ironia (Correia, 2004). Dos vídeos resultantes do YouTube, destacam-se montagens que procuram desconstruir através da irreverência semântica a mensagem tradicional expressa pela classe politica. Posteriormente, a página do movimento registrou o surgimento de vídeos especialmente concebidos para comentar a agenda do movimento. Aí se encontram canções maioritariamente interpretadas por artistas de rap e de hip-hop que denotam a convergência de estéticas urbanas com ativismo político e social.

Obviamente, estas novas opções estéticas denunciam uma nova forma de ecossistema mediático que apela a uma nova forma de literacia seja pela parte dos produtores seja pela parte dos consumidores. O problema e o fascínio da nova literacia mediática consiste no fato de esta ser cunhada num ambiente de transformação e de experimentação permanentes, em que muitas vezes a possibilidade de distanciamento perante os fenômenos, elemento estruturante de qualquer esforço consciente de literacia, se torna difícil. Entre os problemas a realçar contam-se os seguintes:

a. Multiplicam-se os imperativos sistêmicos que submetem muita da produção desenvolvida pelos novos trabalhadores intelectuais aos ditames da nova economia, com 


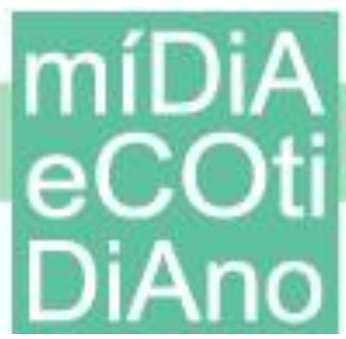

a consequente afirmação das competências empiricas em detrimento do conhecimento hermenêutico e emancipatório.

b. Verifica-se, nos contextos formativos tradicionais, um fosso geracional entre os responsáveis pela formação e os destinatários da mesma, sendo que os primeiros estão habituados a um clima formal de distanciamento teórico e, o segundo, a um clima de imersão e de ausência de distanciamento.

c. Geram-se, frequentemente, dificuldades de partilha de memória que permitam a formação de um background comum de trocas de aprendizagem.

Logo, a nova literacia mediática, produto da velocidade e das potencialidades imersivas e colaborativas dos dispostivos que a estruturam, cria oportunidades mas, simultaneamente, torna-se portadora de novas exigências e demandas. Estas incluem um forte conhecimento das condições colaborativas de autoria intelectual; uma forte consciência do impacto destas novas condições colaborativas na participação política; um aumento da consciência dos riscos deste ecossistema designadamente, dos riscos de dimunuição da atenção crítica e do distanciamento. Tudo isto são oportunidades para uma reinvenção da literacia mediática, simultanaemente consciente da dimensão tecnológica e da dimensão crítico-hermenêutica inerente a qualquer processo de criação intelectual.

\section{Conclusão}

É nesta linha que parece ser mais produtivo contextualizar e compreender acções e protestos levadas a efeito de uma forma ritualista detonando uma nova gramática das identidades politicas. Simplesmente, as suas agendas parecem muito mais centradas na discussão das políticas e não da política não se mostrando particularmente atraídos por propostas utópicas de transformação social total, no sentido que era conferido pelas grandes narrativas da modernidade. Não deixa de ser curioso como um certo radicalismo acional (o prazer da ação), adicionado a uma certa estética da ação são acompanhados por um esforço deliberativo mais processual (convencer) do que substantivo como seja a crença de fundamentar uma solução democrática que permitisse a institucionalização da participação. 
Ao invés, os movimentos europeus de indignados enunciam uma pluralidade de discursos que se manifesta em formas de participação que incluem o afeto, o desabafo, o encolher de ombros, a trivialidade, a fruição lúdica ou o cinismo bem-humorado como estratégia de distanciação ou o desabafo como estratégia de crítica política.

A elaboração conceitual e o dialogismo são relativizados, tendo a dimensão conceitual do movimento sido reduzida, no seu máximo denominador comum, a um manifesto escassamente detalhado. A política institucional e tradicional como forma organizada de racionalizar as sociedades foi substituída por uma atitude que passa em larga medida por uma espontaneidade que interrompe as tradicionais divisões entre racionalidade, ludicidade e afetividade.

Finalmente, preparar as respostas para este novo universo mais líquido e fugaz constitui um desafio para a construção de formas de literacia mediática atentas aos novos dispositivos e aos seus usos por parte de novos atores sociais. Um uso que é mais descentrado e liquefeito, mais ligado ao mundo da vida e menos às práticas institucinais tradicionais, que é ainda portador de incógnitas quanto à sua consequência e efetividade, mas que é parte substancial para a construção dos significados na ação política cotidiana.

\section{Referências Bibliograficas}

CORREIA, João Carlos (2004) Título: Comunicação e Cidadania: os média e a fragmentação do espaço público nas sociedades pluralistas Lisboa, Livros Horizonte, 2004. Páginas: 248 ISBN: 972-24-1318-X

CORREIA, João Carlos. (2011) '12 de Março de 2011: que 'causas' suportam as redes sociais', Conference delivered at the Political Communication Working Group of the 7th Congress of Portuguese Society of Communication (SOPCOM), Lisboa, 15 a 17 de Dezembro de 2011.

FENTON, Natalie (ed.) (2009), New media, old news: journalism and democracy in the digital age, London: Sage. 232 páginas

GEORGE, Éric (2001) «Relecture du concept d'espace public à l'heure de l'Internet». In Émergences et continuité dans les recherches en information et communication, actes du 14 e congrès de la Société française des sciences de l'information et de la communication (SFSIC), pp. 23-31.

HABERMAS, Jürgen (1982), Mudança estrutural da esfera pública, Lisboa, Tempo Brasileiro. 367 páginas.

HABERMAS, Jürgen (1996), Between facts and norms, Cambridge, MIT Press. 675 páginas.

HASSAN, Robert, (2004). Media, politics and the network society, Open University Press. 158 páginas. 
HARDT, Michael e NEGRI, Antonio (2004), Multitude: war and democracy in the Age of Empire, New York: Penguin Press. 448 páginas.

HERRERA, Linda, (2015) "Revolution in the Age of Social Media. The Egyptian Popular Insurrection and the Internet". London, Verso. 192 páginas-

LÉVY, Pierre, (1997a), Cyberculture. Rapport au Conseil de l'Europe dans le cadre du projet Nouvelles technologies: coopération culturelle et communication, Paris: Odile Jacob. 313 páginas.

LÉVY, Pierre. (1997b). «La cyberculture en question : critique de la critique », La Revue du MAUSS, $n^{o}$ 9 (1er semestre), p. 111-126

PAPACHARISSI, Zizi. (2004) 'Democracy online: Civility, politeness, and the democratic potential of online political discussion groups', New Media \& Society, 6(2): 259-83.

PROULX, Serge. (2002) « Mondialisation et mouvements d'affirmation identitaire: expressions possibles de la société civile internationale », in Francis Jauréguiberr \& Serge Proulx (sous dir.), Internet, nouvel espace citoyen? Paris, L'Harmattan, 2002, pp. 13-30.

RHEINGOLD, H. (2000). The Virtual Community: Homesteading on the Electronic Frontier. Revised Edition. Cambridge: MIT Press.

SILVA, Patrícia e GARCIA, José Luís (2012). «YouTubers as satirists. Humor and remix in online video» in P JeDEM 4(1): 89-114, 2012 ISSN 2075-9517

http://www.jedem.org CC: Creative Commons License, 2012.

SOEIRO, José (2014). Da Geração à Rasca ao Que se Lixe a Troika. Portugal no novo ciclo internacional de protesto. Sociologia, Revista da Faculdade de Letras da Universidade do Porto, Vol. XXVIII, 2014, pág. 55 - 79

SUNSTEIN, Cass R. (2001,) Republic.com, Princeton: Princeton University Press. 236 páginas.

TURKLE, Sheryl. (1995). Life on the Screen: Identity in the Age of the Internet, New York: Simon \& Schuster. 352 páginas.

TURKLE, Sheryl. (2011), Alone together: why we expect more from technology and less from each other, New York, Basic Books. 384 páginas. 